\title{
Estimation of bisphenol A influence on obesity
}

Milica Medić Stojanoska ${ }^{1 *}$, Nataša Milioševć ${ }^{2}$, Vladimir Jakšićs ${ }^{3}$ Bojan Vukovićc ${ }^{4}$ Andrijana Milankov ${ }^{1}$, Ivanka Perčić $^{4}$ Tijana Ičin ${ }^{1}$, Branka Kovačev Zavišićc ${ }^{1}$, Nataša Milić ${ }^{2}$

${ }^{1}$ Clinic for Endocrinology, Diabetes and Metabolic Diseases, Clinical Center of Vojvodina, Faculty of Medicine, University of Novi Sad, Serbia

2 Department of Pharmacy, Faculty of Medicine, Univeristy of Novi Sad, Serbia

${ }^{3}$ Faculty of Medicine, University of Novi Sad, Serbia

${ }^{4}$ Emergency Center, Clinical Center of Vojvodina, Faculty of Medicine, University of Novi Sad, Serbia

\section{Introduction}

Obesity is a global health problem. More than half (54\%) of the adult population in Serbia and $58.5 \%$ of adult population in the north province, Vojvodina is obese or overweight [1]. Hence, it is urgent to identify environmental factors which may contribute obesity. Bisphenol A (BPA) is one of the most extensively used chemical in production of food and beverage containers, epoxy resins, polycarbonate plastics [2] and well known endocrine disruptor [3].

The aim of this study is to determine the prevalence of BPA in urine samples in women in Vojvodina and to determine the association between BPA and obesity in women.

\section{Methods}

In the study 103 women age between 18 and 55 were enrolled and in their urinary BPA was determined. Women were divided according to their body mass index (BMI) into two groups: $\mathrm{N}$-normal weight $\left(\mathrm{BMI}<25 \mathrm{~kg} / \mathrm{m}^{2}\right)$ and O-obese group (BMl $\left.\geq 30 \mathrm{~kg} / \mathrm{m}^{2}\right)$.

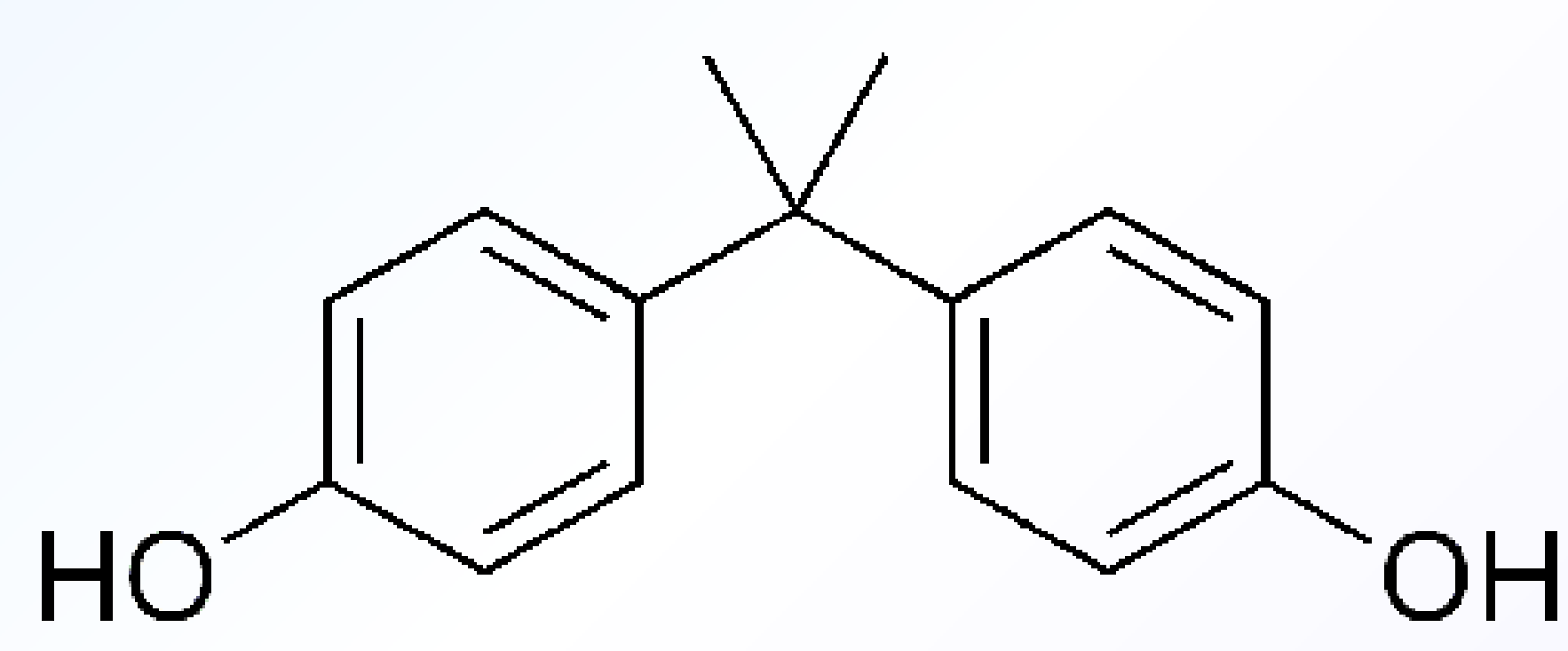

Bisphenol A (BPA)

\section{Results}

BPA was detected in 36\% (37/103) women, 31\% (16/52) in the $\mathrm{N}$-group and $41 \%(21 / 51)$ in the O-group. No statistical difference, odds ratio $1.57(95 \% \mathrm{Cl} 0.70-3.54, \mathrm{p}=0.27)$ was determined in the number of women exposed to BPA according to their BMI. The average concentration of BPA was $12.2410 .55 \mu \mathrm{g} / \mathrm{g}$ creatinine. The groups were additionally divided into two subgroups: BPA positive (BPA+) and BPA negative (BPA-). There was statistically significant linear correlation between BPA concentration in the urine sample and BMI $(r=0.59, p=0.003)$ as well as between waist circumference and $B M I(r=0.45$, $p=0.02$ ) in the O-group. However, no statistical difference was found between BMI, waist circumference, or lipid status: HDL, LDL and total cholesterol among BPA+ and BPA- subgroups in both $\mathrm{N}$ - and O-group. The highest BPA concentrations were detected in younger women with highest $\mathrm{BMI}\left(r^{2}=0.37 \mathrm{p}=0.006\right)$.

Characteristics of the N-normal weight group

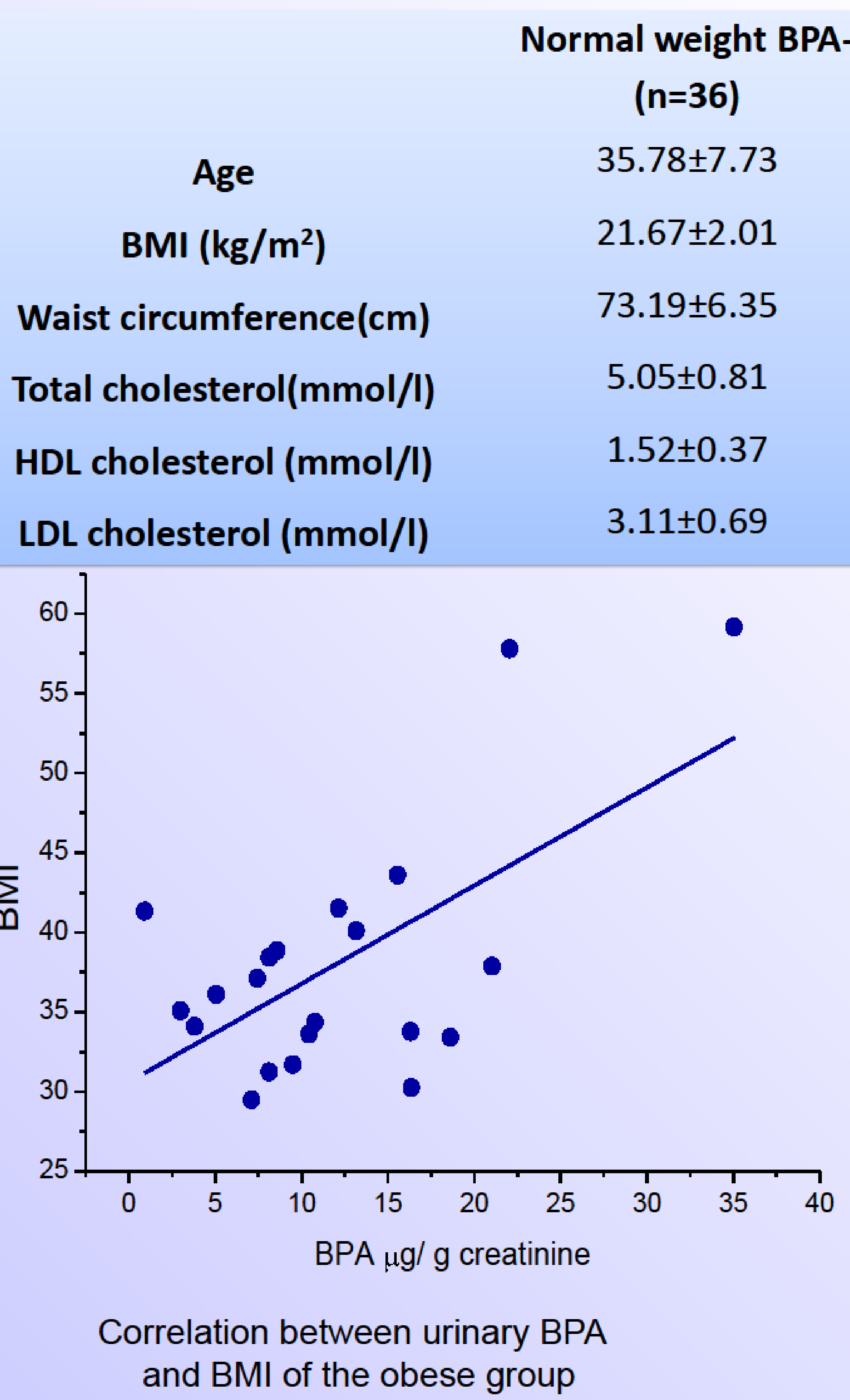

Correlation between urinary BPA

\section{Characteristics of the O-obese group}

\begin{tabular}{cccc}
\multicolumn{4}{c}{ Characteristics of the O-obese group } \\
& $\begin{array}{c}\text { Obese BPA- } \\
(\mathbf{n}=\mathbf{3 0}) \\
\text { Age }\end{array}$ & $\begin{array}{c}\text { Obese BPA+ } \\
(\mathbf{n = 2 1 )}\end{array}$ & $\mathbf{p}$ \\
BMI $\left(\mathbf{k g} / \mathrm{m}^{2}\right)$ & $30.77 \pm 9.02$ & $37.33 \pm 10.08$ & 0.21 \\
Waist circumference(cm) & $106.37 \pm 11.84$ & $113.05 \pm 17.90$ & 0.11 \\
otal cholesterol $(\mathbf{m m o l} / \mathrm{I})$ & $5.25 \pm 0.89$ & $5.27 \pm 1.48$ & 0.96 \\
DL cholesterol $(\mathbf{m m o l} / \mathbf{l})$ & $1.29 \pm 0.35$ & $1.19 \pm 0.37$ & 0.34 \\
DL cholesterol $(\mathbf{m m o l} / \mathbf{l})$ & $3.29 \pm 0.73$ & $3.39 \pm 1.17$ & 0.70
\end{tabular}

\section{Conclusion}

BPA is one of the most important factors which may contribute the increment of $\mathrm{BMI}$ and waist circumference, while HDL, LDL and total cholesterol may be associate factors which additionally influence obesity.

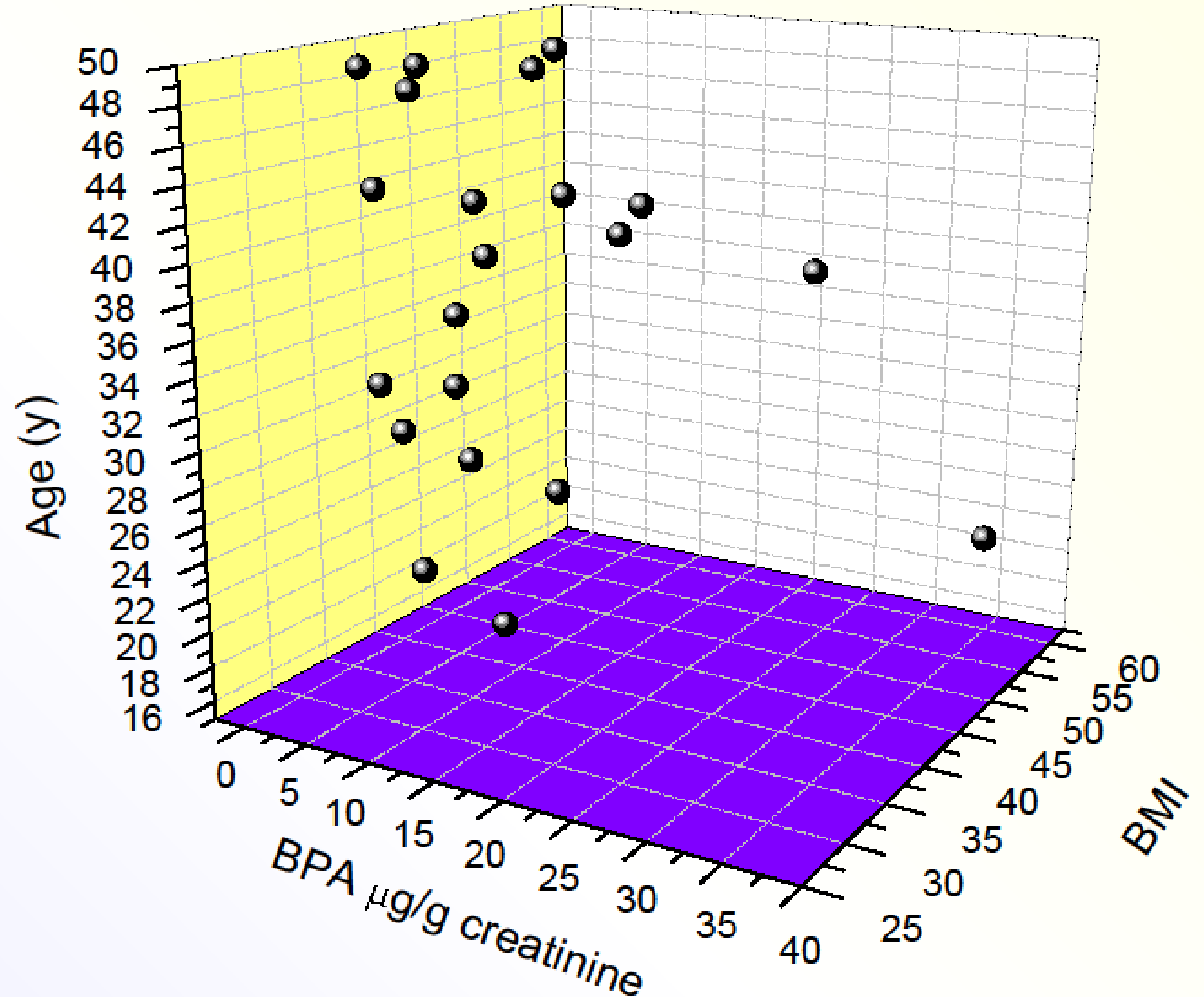

Multiple linear regression of BMI with urinary BPA and age of the obese subjects
Correlation between urinary BPA and waist circumference of the obese group

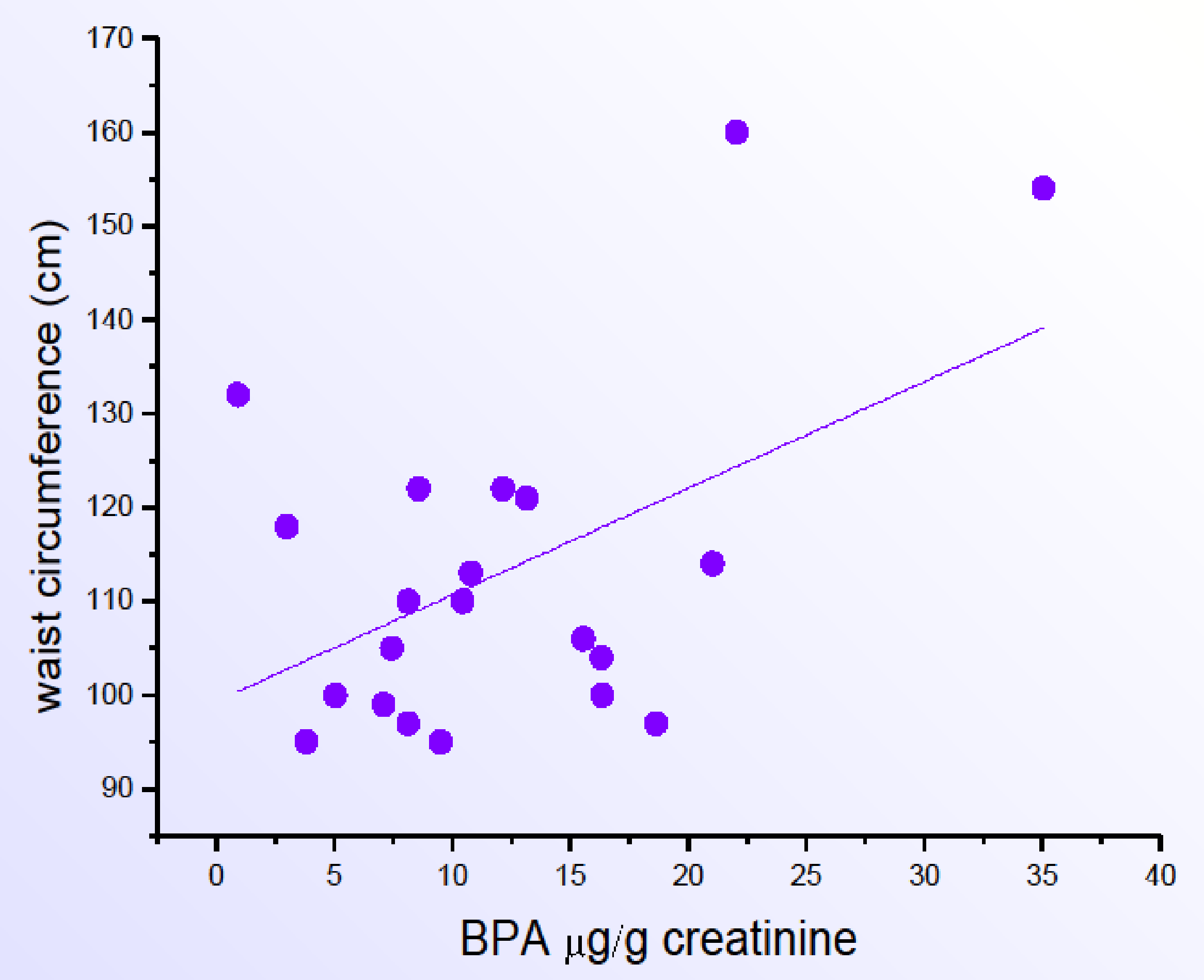

References

Serbian National guidlines for obesity (2004) Ministry of Health, Republic of Serbia.

2. Vom Saal FS, Nagel SC, Coe BL, Angle BM, Taylor JA (2012) The estrogenic endocrine disrupting chemical bisphenol A (BPA) and obesity. Mol Cell Endocrinol 354:74-84.

3. Huang YQ, Wong CK, Zheng JS, BouWMan H, Bara R, Wahistrom B, Neretin L, Wong MH 201 (2012) Bisphenol A (BPA) in China: a review of sources, environmental levels, and potential human health mpacts. Environ Int 42:91-99.
Milica Medic Stojanoska 22. Endocrine Disruptors EP584 